\title{
Вяжущие вещества на основе механоактивированных серпентинсодержащих горнопромышленных отходов
}

Калинкин А.М., Гуревич Б.И., Калинкина Е.В., Залкинд О.А., Серова Е.С.

Институт химии и технологии редких элементов и минерального сырья им. И.В. Тананаева КНЦ PAH, Anamumbl,kalinkin@chemy.kolasc.net.ru

Аннотация. В работе изучена возможность использования механоактивированных серпентинсодержащих горнопромышленных отходов без их предварительного обжига в качестве высокодисперсной минеральной добавки при получении композиционных вяжущих на основе портландцемента, а также в качестве исходного сырья при получении вяжущих щелочной активации.

Ключевые слова: горнопромышленные отходы, механоактивация, антигорит, портландцемент, вяжущие щелочной активации.

\section{Binders based on mechanically activated serpentine-bearing mine wastes}

Kalinkin A.M., Gurevich B.I., Kalinkina E.V., Zalkind O.A., Serova E.S.

Tananaev Institute of Chemistry -Subdivision of the Federal Research Centre KSC RAS, Apatity, kalinkin@chemy.kolasc.net.ru

Abstract. This work studies the possibility of using mechanically activated serpentine-bearing mining wastes without their prior roasting as a highly dispersed mineral additive to produce composite binders based on Portland cement, as well as a raw material to produce alkaline activation binders.

Key words: mining wastes, mechanical activation, antigorite, Portland cement, alkali-activated binders.

\section{Введение}

Актуальной задачей современного строительного материаловедения является разработка способов получения эффективных вяжущих с применением горнопромышленных отходов. В данной статье представлены результаты наших исследований по использованию серпентинсодержащих хвостов обогащения сульфидных медно-никелевых руд комбината «Печенганикель» $(\mathrm{XO})$ в составе композиционного портландцемента (ПЦ) и вяжущего щелочной активации. При получении вяжущего щелочной активации кроме ХО для сравнения использовали также мономинеральную фракцию антигорита (массив Пильгуярви Кольского полуострова), который составляет основу ХО.

Минеральный состав компонентов, мас. \%:

- клинкер: $\mathrm{C}_{2} \mathrm{~S}-20, \mathrm{C}_{3} \mathrm{~S}-53, \mathrm{C}_{3} \mathrm{~A}-7, \mathrm{C}_{4} \mathrm{AF}-12$;

- ХО: антигорит 65-75; тальк 4-20; оливины, пироксены, амфиболы - 0.2-20; магнетит 5.0-15; сульфиды (пирротин, пирит, пентландит, халькопирит) - 1-3.

Химический состав компонентов приведен в табл. 1.

Таблица 1. Химический состав компонентов, мас. \%.

Table 1. Chemical composition of components, wt. \%.

\begin{tabular}{|c|c|c|c|c|c|c|c|c|c|c|c|c|c|}
\hline Компонент & $O^{N}$ & $\stackrel{O}{u}^{n}$ & ○ & $\stackrel{O}{N}_{N^{N}}^{n}$ & $\overbrace{\tilde{U}}^{0}$ & $\begin{array}{l}0 \\
\sum_{i}^{\infty}\end{array}$ & $\begin{array}{l}0 \\
\tilde{z}^{N}\end{array}$ & $\underset{v}{0}$ & $\stackrel{O}{\Xi}_{\sharp}^{N}$ & $O^{n}$ & $\overbrace{\infty}^{m}$ & 吂 & 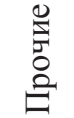 \\
\hline Клинкер & 22.65 & 4.96 & - & 3.27 & 63.35 & 2.12 & 1.0 & 0.67 & - & 0.30 & 1.14 & 1.65 & - \\
\hline $\mathrm{XO}$ & 35.30 & 19.83 & 2.51 & 7.38 & 8.62 & 1.30 & 8.61 & 5.15 & 6.20 & 3.60 & - & - & 1.5 \\
\hline Антигорит & 38.74 & 1.29 & 8.83 & 3.99 & 0.66 & 33.82 & 0.06 & 0.05 & - & - & - & 11.14 & 1.42 \\
\hline
\end{tabular}


Для повышения реакционной способности ХО и антигорита использована механическая активация (МА) сырья без его предварительного обжига.

\section{Смешанные цементы на основе ПЦ и ХО}

Количество ХО, вводимых в ПЦ, изменяли от 5 до 70 мас. \%. Приготовленные смеси подвергали совместной МА в лабораторной центробежно-планетарной мельнице АГО-2 (Аввакумов, 1986) в течение 240 с. Соотношение шары (диаметром 8 мм) : загрузка равнялось $6: 1$. Удельную поверхность $\left(\mathrm{S}_{\mathrm{yz}}\right)$ смесей определяли по методу воздухопроницаемости.

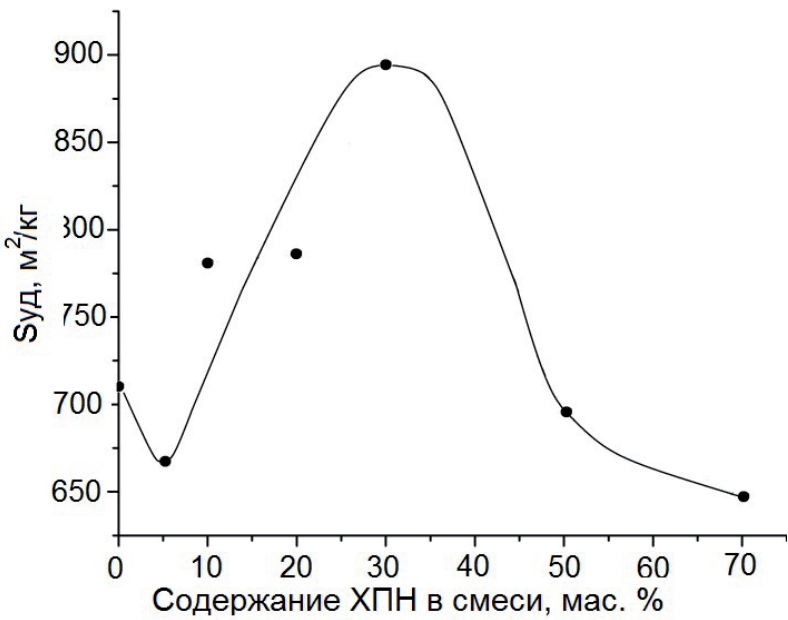

Рис. 1. Зависимость Зуд смеси ПЦ-ХО при совместной МА в течение 240 с от состава смеси.

Fig. 1. Relation between Srel of Portland cement and antigorite-bearing mixture after joint milling for $240 \mathrm{~s}$ as a function of the mixture composition.

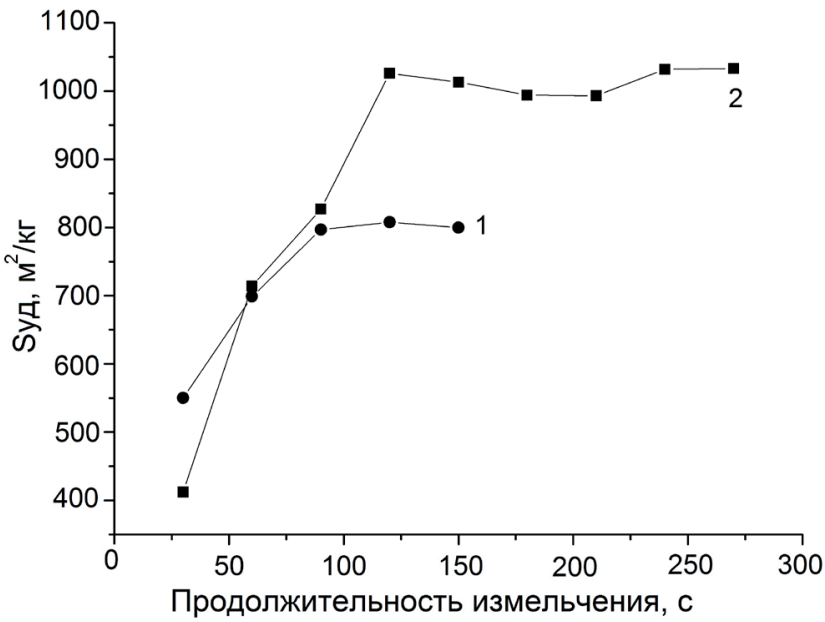

Рис. 2. Зависимость величины Sуд клинкера и ХО при их раздельном помоле от времени измельчения: 1 - клинкер, 2 - ХО.

Fig. 2. Relation between Srel of PC clinker (1) and antigorite-bearing tailings (2) as a function of the milling time in the course of separate milling.

Таблица 2. Влияние добавки ХО к ПЦ клинкеру и 5 мас. \% гипса на прочность при сжатии $\left(\mathrm{R}_{\text {сж }}\right)$ образцов, твердеющих во влажных условиях $(\mathrm{B} / Ц=0.31$, состав 1:0).

Table 2. The effect of the addition of antigorite-bearing tailings to PC clinker with $5 \mathrm{wt} \%$ of gypsum on compressive strength of samples hardened in wet conditions (water/cement $=0.31$, composition 1:0).

\begin{tabular}{|c|c|c|c|c|c|c|c|c|c|c|c|c|c|c|c|}
\hline \multirow{2}{*}{ 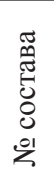 } & \multicolumn{2}{|c|}{$\begin{array}{c}\text { Состав, } \\
\text { мас. } \%\end{array}$} & \multirow{2}{*}{$\begin{array}{c}\text { Sуд, } \text { M }^{2} \\
\text { кг }\end{array}$} & \multicolumn{4}{|c|}{$\mathrm{R}_{\text {сж }}$ через....сут, МПа } & \multicolumn{4}{|c|}{$\mathrm{R}_{\text {сж }}, \%$ через....сут } & \multicolumn{4}{|c|}{$\Delta \mathrm{R}_{\text {сж}} \%$ через....сут } \\
\hline & 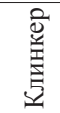 & $\mathrm{XO}$ & & 7 & 28 & 180 & 360 & 7 & 28 & 180 & 360 & 7 & 28 & 180 & 360 \\
\hline б/H & 100 & - & 710 & 48.3 & 58.3 & 69.5 & 70.6 & 100 & 100 & 100 & 100 & - & - & - & - \\
\hline 1 & 95 & 5 & 668 & 45.7 & 54.0 & 57.8 & 59.9 & 94.6 & 92.6 & 83.2 & 84.8 & -0.4 & -2.4 & 11.8 & -10.2 \\
\hline 2 & 90 & 10 & 781 & 55.7 & 60.3 & 61.2 & 68.9 & 115 & 103 & 88.1 & 97.6 & 25 & 13 & 1.9 & 7.6 \\
\hline 3 & 80 & 20 & 786 & 39.4 & 51.9 & 52.0 & 68.5 & 81.6 & 89.0 & 74.8 & 97.0 & 1.6 & 9 & 5.2 & 17.0 \\
\hline 4 & 70 & 30 & 894 & 40.9 & 41.9 & 45.7 & 50.7 & 84.7 & 71.9 & 65.8 & 71.8 & 14.7 & 1.9 & 4.2 & 1.8 \\
\hline 5 & 50 & 50 & 697 & 34.2 & 42.8 & 41.1 & 45.1 & 70.8 & 73.4 & 59.0 & 63.9 & 20.8 & 7.2 & 9.0 & 13.9 \\
\hline 6 & 30 & 70 & 647 & 22.9 & 26.3 & 30.6 & 33.7 & 47.4 & 45.1 & 44.0 & 47.7 & 17.4 & 15.1 & 14.0 & 17.7 \\
\hline
\end{tabular}

Зависимость $\mathrm{S}_{\text {уд }}$ смеси от ее состава при одинаковом времени совместной MA $(240 \mathrm{c})$, имеет сложный характер (рис. 1). С увеличением содержания хвостов в смеси до 30-40 мас. \% $\mathrm{S}_{\text {уд }}$ смеси после некоторого уменьшения начинает расти и превосходит $\mathrm{S}_{\text {уд }}$ чистого ПЦ. При дальнейшем увеличении добавки $\mathrm{XO}$ величина $\mathrm{S}_{\text {уд }}$ уменьшается. Размалываемость хвостов, обусловленная их минеральным составом, выше, чем у клинкера (рис. 2), поэтому, по-видимому, с увеличением содержа- 
ния хвостов в смеси, главным образом, происходит размол хвостов, а не клинкера, частицы которого распределены в массе хвостов и менее доступны воздействию мелющих тел.

Для определения вяжущих свойств композиций изготавливались образцы размером $1.41 \times 1.41 \times 1.41$ см из теста пластичной консистенции, которые твердели во влажных условиях при температуре $20-22^{\circ}$ С. Результаты экспериментов приведены в таблице 2. Данные по прочности при сжатии, приведенные в таблице 2, показывают, что при твердении композиций ХО - клинкер - гипс (5 мас. \%) для всех составов (кроме состава №1) и сроков твердения получаем прочность, превосходящую расчетную величину, определенную на основе содержания ПЦ клинкера в композиции, считая, что ХО - инертный наполнитель. Относительный прирост прочности составляет от 1.9 до 25 \%. Строгой корреляции между составом механоактивированных смесей, их удельной поверхностью и прочностью нет, по-видимому, из-за сложного характера распределения частиц по размерам и других факторов, влияющих на процесс образования цементного камня.

Проведенные исследования показали, что ХО можно рассматривать как гидравлическую добавку при помоле ПЦ.

\section{Геополимерные вяжущие на основе механоактивированных ХО}

Исследована возможность использования ХО в качестве компонентов геополимеров без их предварительного обжига, при этом повышение активности обеспечивалось за счет МА в центробежно-планетарной мельнице АГО-2 (Kalinkina et al., 2018). Среди факторов, являющихся следствием МА и влияющих на повышение реакционной способности ХО и антигорита, рассмотрены изменения величины удельной поверхности, степени аморфизации, дегидроксилирования.

Характер изменения $\mathrm{S}_{\text {уд }}$ от времени МА показывает, что МА антигорита и ХО в течение 6-10 мин обеспечивает фактически максимально возможную в данных условиях удельную поверхность частиц. $\mathrm{S}_{\text {уд }}$ порошков плавно возрастает до 30 и 23 м²/г, выходя на плато к 8-10 мин МА, для антигорита и ХО соответственно (рис. 3). Меньшая величина удельной поверхности хвостов, вероятно, связана с различиями в минеральном составе.

Согласно литературным данным (Dlugogorski et al., 2014, Jolicoeur et al., 1981, Martinez, 1961), при термической активации серпентинов увеличение степени их дегидроксилирования, оцененная

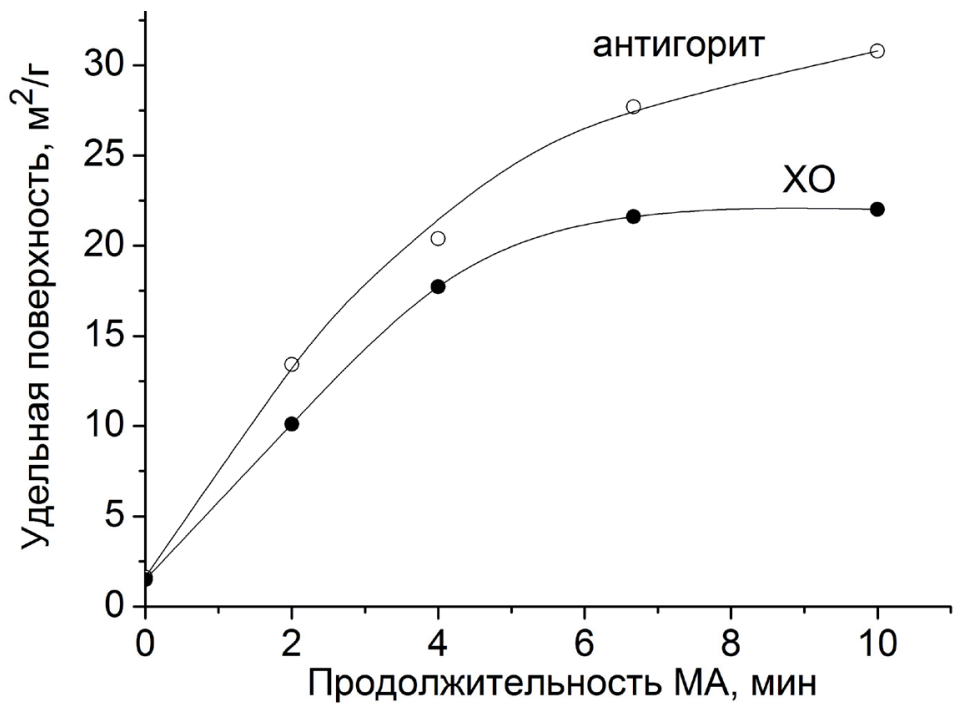

Рис. 3. Зависимость удельной поверхности антигорита и ХО от продолжительности МА (метод низкотемпературной адсорбции азота).

Fig. 3. Relation between specific surface area of antigorite and antigorite-bearing tailings and the duration of milling (low-temperature nitrogen adsorption method). по содержанию остаточных структурных гидроксильных групп в обезвоженном материале, при условии отсутствия кристаллизации форстерита, строго коррелирует с увеличением активности и используется в качестве критерия повышения реакционной способности серпентинов, в частности, при взаимодействии с углекислым газом. На рисунке 4 представлены данные о степени аморфизации антигорита в условиях механической активации в АГО-2, определенные по соотношению высоты основного пика исходного и механоактивированного антигорита, а также остаточное содержание структурной воды в антигорите (в \% от исходного содержания), оцененное по данным термического анализа. Эти данные сопоставлены с прочностными характеристиками полученных вяжущих. 


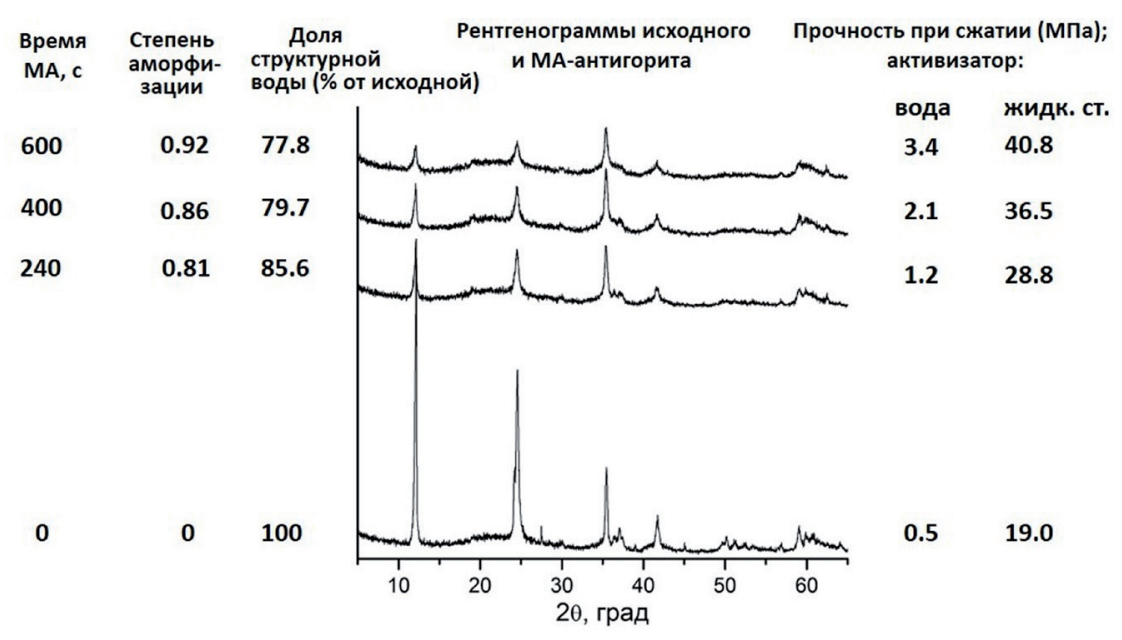

Рис. 4. Данные РФА и зависимости степени аморфизации, доли остаточной структурной воды антигорита и прочности при сжатии образцов антигорита от времени МА.

Fig. 4. The XRD data and dependences of the degree of amorphization, the proportion of residual structural water of antigorite and compressive strength of antigorite samples on the duration of milling.

Содержание остаточных структурных гидроксильных групп, согласно расчету по результатам ДТА-ТГ (не приведены), уменьшается от 100 \% в исходном антигорите до 77.8 \% в продукте 10-минутной активации.

Этот вывод подтверждается данными ИК спектроскопии (рис. 5), согласно которым интенсивность узкой полосы валентных колебаний структурных ОН групп при 3675 см$^{-1}$ снижается в результате МА. Одновременно наблюдается увеличение интенсивности широкой полосы в области 3500-3350 см-1 , отвечающей валентным колебаниям гидроксильных групп в молекулярной воде, образовавшейся в результате рекомбинации структурных гидроксилов.

Эти результаты в сочетании с данными по прочности свидетельствуют, что МА антигорита и, предположительно, хвостов обогащения, увеличивают активность изначально инертного серпентинсодержащего сырья до уровня, позволяющего использовать их в качестве компонента геополимеров.

При подборе условий синтеза геополимеров на основе механоактивированного антигоритсодержащего сырья и концентрированных растворов силикатов натрия (жидкого стекла - ЖС) варьировали следующие параметры: продолжительность МА исходного сырья, количество ЖС (содержание $\mathrm{Na}_{2} \mathrm{O}$ в ЖС по отношению к массе сырья в составе композиции) и условия твердения (воздушно-сухие или влажные). Согласно полученным результатам, композиции «механоактивированные ХО - ЖС» являются в большей степе-

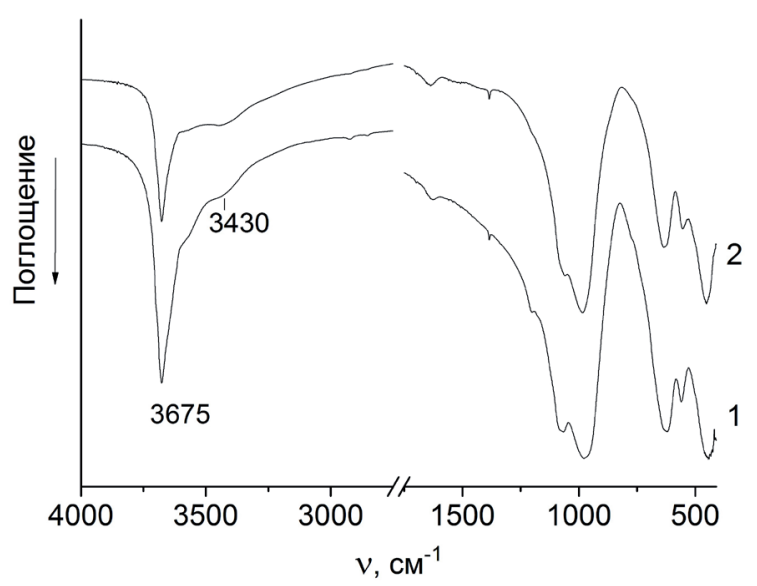

Рис. 5. ИК спектры: 1 - исходный антигорит; 2 - после 10 мин МА.

Fig. 5. Infrared spectra of 1 - initial antigorite, 2 - antigorite milled for $10 \mathrm{~min}$. ни воздушным вяжущим, но также твердеют и во влажных условиях. Увеличение продолжительности МА ХО от 60 с до 240 с ведет к увеличению прочности при сжатии геополимерного материала, достигая величины 15 МПа при влажном твердении, и 49 МПа при воздушно-сухом твердении для времени твердения 28 сут. Наилучшие результаты по прочности при модуле ЖС 3.18 дают составы, содержащие 4 \% $\mathrm{Na}_{2} \mathrm{O}$ (рис. 6).

МА повышает реакционную способность антигорита в композиции «антигорит - жидкое стекло». Прочности цементного камня на основе исходного и МА-антигорита для воздушных условий твердения при выбранных условиях синтеза в возрасте 28 сут составляют 19.0 и 40.8 МПа соответственно (рис. 4, табл. 3). Замена антигорита на антигоритсодержащие хвосты обогащения в геопо- 

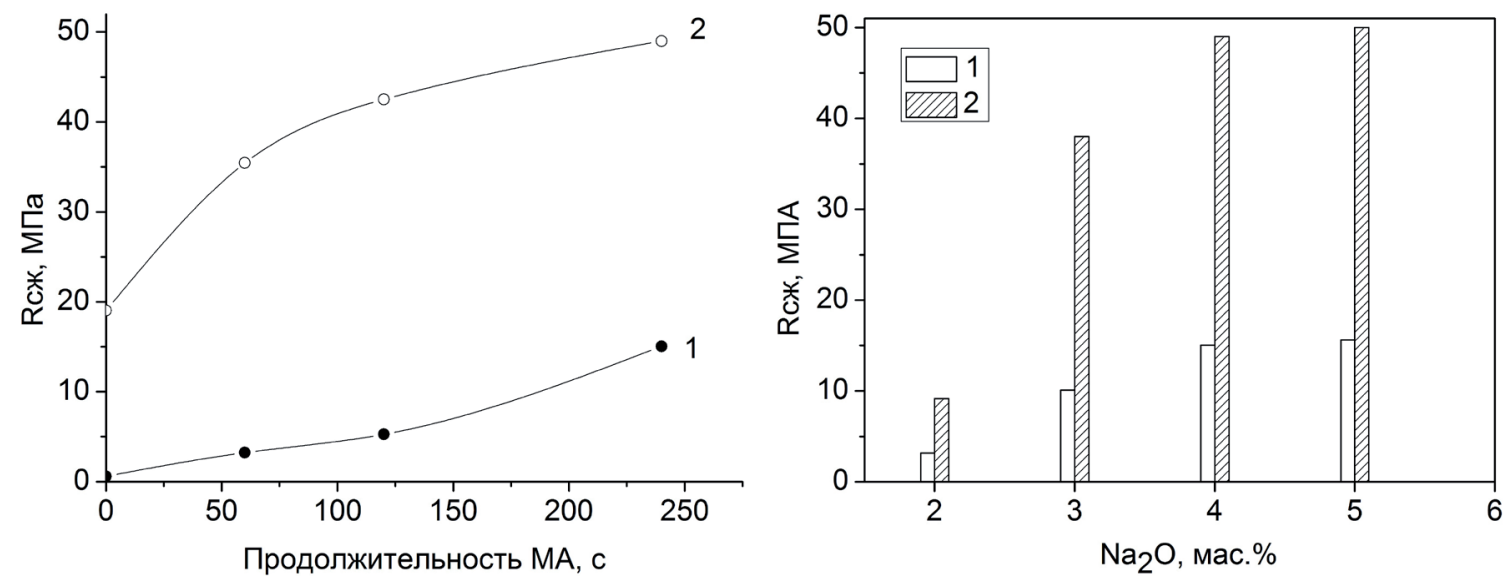

Рис. 6. Зависимость прочности при сжатии $\left(\mathrm{R}_{\text {сж) }}\right.$ ) композиции «механоактивированные $\mathrm{XO}$ - ЖС» (модуль ЖС - 3.18; $\mathrm{Na}_{2} \mathrm{O}-4 \%$ ) от продолжительности МА ХО (а) и от количества ЖС (б) при модуле ЖС 3.18 и времени МА 240 с. Условия твердения: 1 - влажные, 2 - воздушно-сухие.

Fig. 6. The dependence of the compressive strength $\left(\mathrm{R}_{\mathrm{cK}}\right)$ of the composition «milled antigorite-containing tailings - liquid glass») (liquid glass modulus 3.18; $\mathrm{Na}_{2} \mathrm{O}-4 \%$ ) on the duration of milling of the tailings (a) and the amount of liquid glass (б) with liquid glass modulus 3.18 and milling time 240 s. Hardening conditions: 1 - wet, 2 - air dry.

лимерной композиции приводит к снижению прочности при воздушном твердении на 225 \% (в возрасте 28 сут) за счет «разбавления» антигорита инертными компонентами (тальк и др.), но в ходе дальнейшего твердения (к 180 сут) разница в величинах $\mathrm{R}_{\text {сж }}$ уменьшается до 12 \% (табл. 3).

Таблица 3. Прочность при сжатии $\left(\mathrm{R}_{\text {сж}}\right)$ механоактивированных в течение 10 мин антигорита и ХО ( $\mathrm{S}_{\text {уд }}$ измерена методом воздухопроницаемости), активизатор - жидкое стекло

(модуль 2.25 , количество $\mathrm{Na}_{2} \mathrm{O}-3 \%$ ).

Table 3. The compressive strength $\left(\mathrm{R}_{\mathrm{cm}}\right)$ of antigorite and the antigorite-containing tailings $(\mathrm{XO})$ milled for $10 \mathrm{~min}$. The specific surface area was measured by Blaine method. Activator - liquid glass

(liquid glass modulus 2.25; amount of $\mathrm{Na}_{2} \mathrm{O}-3 \%$ ).

\begin{tabular}{|l|c|c|c|c|c|c|c|}
\hline \multirow{2}{*}{ Материал } & \multirow{2}{*}{$\mathrm{S}_{\text {уд }}, \mathrm{M}^{2} / \mathrm{\kappa г}$} & \multirow{2}{*}{ Условия твердения } & \multirow{2}{*}{$\mathrm{B} / \mathrm{T}$} & \multicolumn{4}{|c|}{$\mathrm{R}_{\text {сж }}, \mathrm{MПа}$} \\
\cline { 5 - 8 } & & & & 1 сут. & 7 сут. & 28 сут. & 180 сут. \\
\hline антигорит & 1259 & воздушное & 0.26 & 12.2 & 20.6 & 40.8 & 36.8 \\
\hline антигорит & 1259 & влажное & 0.26 & 3.5 & 4.1 & 5.3 & 5.8 \\
\hline ХО & 1280 & воздушное & 0.22 & 10.8 & 22.6 & 30.8 & 32.5 \\
\hline ХО & 1280 & влажное & 0.25 & 6.8 & 8.7 & 7.8 & - \\
\hline
\end{tabular}

Таким образом, проведенные исследования показали, что МА в течение 4-6 мин в энергонапряженной мельнице АГО-2 повышает реакционную способность серпентинсодержащего сырья до уровня, позволяющего эффективно использовать его в качестве высокодисперсной минеральной добавки при получении композиционных вяжущих на основе портландцемента, а также в качестве исходного сырья при получении щелочеактивируемых вяжущих воздушного твердения.

\section{Литература}

1. Аввакумов Е.Г. Механические методы активации химических процессов. Новосибирск: Наука. 1986. 305 с.

2. Dlugogorski BZ, Balucan RD. Dehydroxylation of serpentine minerals: implications for mineral carbonation. Renewable and Sustainable Energy Reviews. 2014. 31. P. 353-367.

3. Jolicoeur C, Duchesne D. Infrared and thermogravimetric studies of the thermal degradation of chrysotile asbestos fibers: evidence for matrix effects // Canadian Journal of Chemistry. 1981. 59. P. 1521-1526.

4. Kalinkina E.V., Gurevich B.I., Kalinkin A.M. Alkali-activated binder based on milled antigorite // Minerals. 2018. 8(11). P. 503.

5. Martinez E. The effect of particle size on the thermal properties of serpentine minerals // American Mineralogist. 1961. 46. P. 901-912. 